\title{
A ESCRITA COMO PATRIMÔNIO: O QUEIJO E OS VERMES, DE CARLO GINZBURG E SUA INFLUÊNCIA NA HISTORIOGRAFIA CONTEMPORÂNEA
}

\author{
Angelo Adriano Faria de Assis ${ }^{1}$ \\ Yllan de Mattos $^{2}$
}

\begin{abstract}
Resumo: Este artigo tem como objetivo analisar o impacto na historiografia, tanto internacional quanto brasileira, da obra $O$ Queijo e os Vermes, do historiador italiano Carlo Ginzburg, lançada em 1976 na Itália e depois traduzida e publicada em vários países. Neste sentido, o trabalho traça uma breve apresentação da biografia e da produção historiográfica do autor, dos destacados representantes da Micro-História, e analisa as principais ideias presentes em $O$ Queijo e os Vermes, bem como sua aceitação e críticas. Passados mais de quarenta anos de sua publicação, busca-se compreender a influência que este trabalho continua a exercer sobre os estudos produzidos por historiadores de todo o mundo.
\end{abstract}

Palavras-chave: Carlo Ginzburg. O Queijo e os Vermes. Historiografia.

\section{WRITING AS HERITAGE: THE CHEESE AND THE WORMS, BY CARLO GINZBURG AND HIS INFLUENCE ON CONTEMPORARY HISTORIOGRAPHY}

Abstract: This article aims to analyze the impact of the work of Italian historian Carlo Ginzburg on international and Brazilian historiography, The Cheese and the Worms, published in 1976 in Italy and later translated and published in several countries. In this sense, the work traces a brief presentation of the biography and the historiographical production of the author, one of the outstanding representatives of Microhistory, and analyzes the main ideas present in The Cheese and the Worms, as well as their acceptance and criticism. After more than forty years of its publication, we seek to understand the influence that this work continues to exert on the studies produced by historians around the world.

Keywords: Carlo Ginzburg. The Cheese and the Worms. Historiography.

\section{L'ÉCRITURE COMME PATRIMOINE: LE FROMAGE ET LES VERS, DE CARLO GINZBURG ET SON INFLUENCE SUR L'HISTORIOGRAPHIE CONTEMPORAINE}

Résumé: Cet article analyse l'impact sur l'historiographie internationale et brésilienne d'ouvre Le Fromage et les Vers, de l'historien italien Carlo Ginzburg, publié en 1976 en Italie et ultérieurement traduit et publié dans plusieurs pays. En ce sens, l'article trace une brève présentation de la biographie et de la production historiographique de l'auteur, des éminents représentants de la microhistoire, et analyse les idées principales présentes dans Le Fromage et les Vers, ainsi que leur acceptation et leur critique. Après plus de quarante ans de sa publication, on a cherché de comprendre l'influence que ce travail continue d'exercer sur les études produites par les historiens du monde entier.

\footnotetext{
${ }^{1}$ Doutor em História pela Universidade Federal Fluminense (2004) e Pós-doutorado pela Universidade de Lisboa (2011) e pela Universidade de Évora (2011). Atualmente é Professor Associado III da Universidade Federal de Viçosa. É pesquisador da Cátedra de Estudos Sefarditas "Alberto Benveniste" da Universidade de Lisboa. É Avaliador do SINAES e da REDE Nacional de Ipfes (INEP-MEC). Membro, a partir de 2017, da ABIL (Association of British and Irish Lusitanists).

2 Doutor em História Moderna na Universidade Federal Fluminense (2013). Professor Adjunto no Departamento de História da Universidade Federal Rural do Rio de Janeiro, campus de Seropédica, e Professor Colaborador no Programa de Pós-Graduação em História da Universidade Estadual Paulista Júlio de Mesquita Filho, campus Franca.
} 


\section{Escritas do Tempo/}

Mots-clés: Carlo Ginzburg. Le fromage et les Vers. Historiographie.

\section{LA ESCRITURA COMO PATRIMONIO: EL QUESO Y LOS GUSANOS, DE CARLO GINZBURG Y SU INFLUENCIA EN LA HISTORIOGRAFÍA CONTEMPORÁNEA}

Resumen: Este artículo tiene como blanco analizar el impacto en la historiografía, tanto internacional como brasileña, de la obra El Queso y los Gusanos, del historiador italiano Carlo Ginzburg, lanzada en 1976 en Italia y luego traducida y publicada en varios países. En este sentido, el trabajo traza una breve presentación de la biografía y de la producción historiográfica del autor, de los destacados representantes de la Micro-Historia, y analiza las principales ideas presentes en El Queso y los Gusanos, así como su aceptación y críticas. Pasados más de cuarenta años de su publicación, se busca comprender la influencia que este trabajo sigue ejerciendo sobre los estudios producidos por historiadores de todo el mundo.

Palabras clave: Carlo Ginzburg. El Queso y los Gusanos. Historiografía.

\section{Introdução}

"Cada um faz o seu dever, tem quem ara, quem cava e eu faço o meu dever de blasfemar"

Domenico Scandela, Menocchio

[Archivio della Curia Arcivescovile di Udine, Inquizisione, Proc. 126, fl. $7 v$.

Carlo Ginzburg. Il formaggio e i vermi, p. 6]

Carlo Nello Ginzburg é dos historiadores mais conhecidos e importantes do mundo atual. Nascido em um família de judeus assimilados e intelectuais na Turim de 1939, filho de um professor de literatura russa, tradutor e um dos fundadores da Enciclopédia Einaudi, Leone Ginzburg, que morreria lutando contra o nazifascismo, e da romancista Natalia Ginzburg, das mais famosas e respeitadas escritoras italianas do século $\mathrm{XX}$, autora de várias obras que mesclam a criativade ficcional com os relatos históricos, e que serviria como das grandes inspirações do filho.

Iniciou seus estudos em História na Scuola Normale Superiore de Pisa, e depois no Instituto Warburg, em Londres, Inglaterra. Atuou como professor em diversas instituições, como a Universidade de Bologna, na Itália, e as Universidades de Harvard, Yale, Princeton e Califórnia, nos Estados Unidos da América - nesta última, ocupou durante duas décadas a cadeira de Renascimento Italiano no Departamento de História. Atualmente, é professor de cultura europeia na mesma Escola Normal Superior de Pisa em que se formou.

Autor de uma vasta obra, seus livros foram publicados em dezenas de países e línguas, como italiano, inglês, francês, espanhol, catalão, português, alemão, polonês, 
holandês, sueco, servo-croata, húngaro, grego, turco, romeno, albanês, estoniano, tcheco, finlandês, dinamarquês, norueguês, russo, hebraico, coreano, chinês, japonês, entre outras.

Figura 1: algumas das edições de $O$ Queijo e os Vermes em diferentes países e idiomas

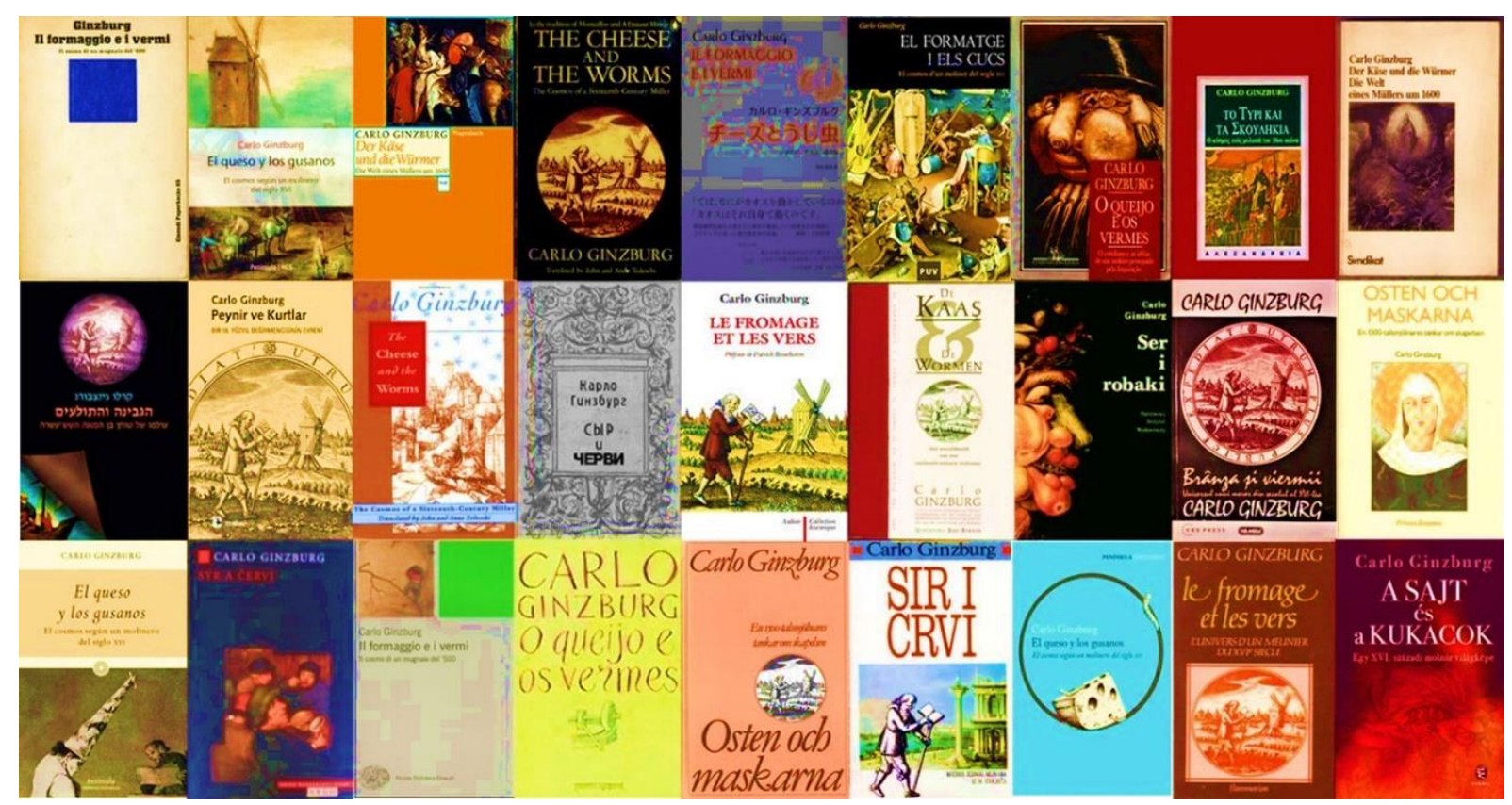

Fonte: todas as imagens estão disponíveis em sites de venda de livros de variados países.

A importância de Carlo Ginzburg e a influência de sua obra para a historiografia contemporânea é largamente reconhecida. Recebeu, por suas obras e contribuição singular para a ciência histórica, várias premiações, como o Aby Warburg Prize (Alemanha), em 1992, o Premio Letterario Viareggio-Rèpaci (Itália), em 1998, o Prêmio Antonio Feltrinelli (Itália) em 2005, e o Prêmio Balzan (Itália - Suíça), em 2010, como personalidade das artes e da cultura. É membro honorário da Academia Americana de Artes e Ciências e colaborador de algumas das mais importantes revistas na área das Ciências Humanas, como Past and Present ${ }^{3}$, Annales ${ }^{4}$ e Quaderni Storici ${ }^{5}$. Um de seus

\footnotetext{
${ }^{3}$ Revista britânica, publicada pela Oxford University Press, fundada em 1952 por historiadores conhecidos como "marxistas", como Edward P. Thompson e Eric Hobsbawn, foi pioneira nos estudos sobre História Social.

${ }^{4}$ Lançada em 1929, na França, com o título de Annales d'histoire économique et sociale pelos historiadores Marc Bloch e Lucien Febvre, firmou-se como referência mundial por sua nova concepção de História e de documento, dando origem a uma revolução historiográfica e, mais tarde, à Nouvelle Histoire, contando com historiadores como Jacques le Goff e Pierra Nora.

${ }^{5}$ Criada em 1966 pelo historiador Alberto Caracciolo, tornou-se uma das mais importantes revistas especializadas italianas e de repercussão internacional, sendo das principais divulgadoras do campo da micro-história, e contou, entre seus colaboradores, com nomes como Pasquale Villani, Giovanni Levi, Edoardo Grendi e Carlo Poni, além do próprio Carlo Ginzburg.
} 
textos mais divulgados no Brasil, "O inquisidor como antropólogo" foi publicado no volume 21 da Revista Brasileira de História (1990-91).

Suas obras mais conhecidas estão todas publicadas em português, (cita-se, aqui, o ano da publicação original): O primeiro livro é já um clássico, e admira não apenas pelo refinamento da escrita, mas igualmente pela profundidade e riqueza de análise, bem como por seu caráter extremamente inovador, para um então jovem pesquisador de apenas 27 anos. O livro contava com elementos novidadescos para a análise histórica, trazendo um tema periférico como a feitiçaria para o centro das discussões. Em Os andarilhos do bem: feitiçarias e cultos agrários nos séculos XVI e XVII (1966), publicado no Brasil em 1988, analisa crenças populares, atitudes e mentalidade religiosas de uma sociedade camponesa entre finais do Quinhentos e meados do Seiscentos na Itália a partir de um culto de fertilidade perseguido pela Igreja e pela Inquisição como práticas de feitiçaria. Em resposta inesperada ao Santo Ofício, afirmavam-se benandanti, ou "andarilhos do bem", informando que combatiam durante a noite as bruxas que empunhavam espigas de milho, armados com talos de erva-doce. Sem dúvida, uma notável contribuição aos estudos sobre religiosidades populares, feitiçarias, e práticas mágico-religiosas na Modernidade.

Indagações sobre Piero ${ }^{6}$ (GINZBURG, 1981) trata do problema de datação da obra do pintor toscano Piero della Francesca (c. 1416-1492), bem como apresenta uma abordagem do célebre pintor diversa daquela estabelecida, articulando sua obra de arte com o contexto social em que estava inserida. O livro inaugurou a célebre coleção Microstorie, organizada na editora Einaudi pelo próprio Ginzburg e pelo historiador conterrâneo Giovanni Levi, este último, autor de outro clássico dos estudos de microanálise, A Herança imaterial. Tal qual Ginzburg, Levi seria um dos responsáveis pela divulgação desta corrente historiográfica, referências incontornáveis no campo dos trabalhos de vertente microanalítica.

Mitos, Emblemas, sinais: morfologia e história (1986) (GINZBURG, 1990) apresenta, de forma mais detalhada, uma das principais facetas de seu trabalho historiográfico - o "saber indiciário", em capítulo conhecidíssimo da obra ("Sinais: raízes de um paradigma indiciário"), explorando o pormenor, a observação de pistas, o faro, os sintomas, os detalhes negligenciados, os indícios diminutos, os dados marginais para a análise das fontes, valorizando a erudição no ofício do historiador... "Deus está no

\footnotetext{
${ }^{6}$ Em edição posterior pela Cosac Naify (São Paulo, 2010), o livro é relançado no Brasil com o título de Investigando Piero.
} 


\section{Escritas do Tempo}

particular", assentado no detalhe, que só um olhar apurado, num paralelismo com o detetivesco e a sagaz percepção médica, é capaz de perceber, no traço, no contrapelo do que não está escrito, do que não se desvenda óbvio.

História noturna: decifrando o sabá (1989) (GINZBURG, 1991), procura, a partir da análise da prática enigmática do sabá - presença do Diabo, banquetes, orgias sexuais, cerimônias antropofágicas, profanações de ritos e crenças cristãs - perceber a sobrevivência e continuidade, mesmo que adaptada, na Modernidade europeia, de uma cultura ancestral antiquíssima, recheada de mitos e de processos de exclusão social contra leprosos, judeus, muçulmanos, hereges, mulheres e bruxas.

Em A Micro-História e outros ensaios (GINZBURG, 1989), Ginzburg reúne um conjunto de textos sobre os temas que percorreu e ainda percorre com maior frequência em sua carreira, como a história da arte, reflexões sobre o trabalho com as fontes, circularidades culturais e religiosidades, a valorização dos estudos de caso, o procedimento indiciário, os estudos da morfologia (forma, configuração, sentido das palavras).

Olhos de madeira: nove reflexões sobre a distância (1998) (GINZBURG, 2001) é tentativa do autor em refletir sobre a perspectiva e a interpretação histórica. $O$ significado dos acontecimentos, define, encontra-se na distância entre eles e nas variadas formas de vê-los. Numa época em que as diferenças entre os homens ameaçam se apagar, em que o mundo fica cada vez mais igual, apresenta análises que mostram o confronto, a diferença, as perspectivas e como estas auxiliam a construir uma história de si a partir do olhar do outro.

Em Relações de força: história, retórica, prova (2000) (GINZBURG, 2002), espécie de sequência de Olhos de Madeira, Ginzburg propõem-se a desmontar a visão pós-moderna da historiografia como prática desobrigada de qualquer objetividade, reafirmando a importância da tradição clássica para a visão de culturas alheias e distantes.

Já em Nenhuma ilha é uma ilha: quatro visões da literatura inglesa (2002) (GINZBURG, 2004), por sua vez, o que interessa ao autor são as trocas literárias e as influências recíprocas entre as ilhas britânicas e o continente europeu, decisivas na formação literária, cultural e mesmo identitária dos ingleses.

O fio e os rastros: verdadeiro, falso, fictício (2006) (GINZBURG, 2007) é uma espécie de reflexão sobre o ofício do historiador e da defesa das virtudes da História como porta de conhecimento da realidade, repensando sobre a natureza da verdade e da 


\section{EscRITAS do T EMPo/}

narrativa, da historiografia e da literatura, na contínua perseguição às pistas mais tênues, fazendo conversar e relacionarem-se fontes diversas na busca da informação.

Medo, reverência, terror: Quatro ensaios de iconografia política (2008) (GINZBURG, 2014), último dos livros do autor publicado no Brasil (primeira edição, aqui, em 2014), investiga os significados de gestos, objetos e palavras em momentoschave do imaginário do Ocidente, partindo de exemplos tão díspares ou supostamente distantes, que vão da Modernidade, com o Leviatã de Thomas Hobbes, aos cartazes propagandísticos das Guerras Mundiais e a Guernica de Picasso, na contemporaneidade do século XX.

Além destes, publicou livros que ainda não foram lançados no mercado editorial brasileiro. Dentre eles, O juiz e o historiador (1991) (GINBURG, 1993), em que reflete sobre as relações e especificidades nas análises de juízes e historiadores a partir da análise um julgamento equivocado da Justiça italiana dos anos 1990 sobre um assassinato ocorrido em 1972. Ou Tentativas, coletânea que reúne ensaios e textos publicados em outras de suas obras, em que Ginzburg, no prefácio que faz da obra, explica a importância da dedicação incansável à pesquisa:

Jogando contra si mesmo, assumir o papel de advogado do diabo, me parecem atitudes indispensáveis em todo aquele que queira desenvolver a investigação no sentido pleno do termo: ou seja, a investigação do novo, sem redes de proteção historiográficas ou ideológicas. Tentativa deriva do latim temptare: tocar, sentir. Quem faz pesquisa é como uma pessoa que está em uma sala escura. Move-se a tatear, colide com um objeto, faz conjecturas. Do que se trata? Da esquina de uma mesa, de uma cadeira, ou de uma escultura abstrata? $\mathrm{Na}$ investigação do que é desconhecido, esquecido e imprevisível, também a sorte pode cumprir uma função útil. Mas seria ingênuo ter ilusões: não existem atalhos para o estudo, e estudar é algo trabalhoso e cansativo (GINZBURG, 2001, p. 43).

Porém, seja no Brasil seja no exterior, o mais conhecido livro de Ginzburg, e que deu ao autor autoridade como historiador e destaque internacional foi, sem dúvida, a obra que dá origem a este artigo, publicado em 1976, na Itália. O queijo e os vermes: o cotidiano e as ideias de um moleiro perseguido pela Inquisição (GINZBURG, 1996), ou Il formaggio e i vermi. Il cosmo di un mugnaio del '500, em título original italiano. Mais uma vez, como fizera com I Benandanti, Ginzburg visita as fontes da Inquisição italiana, explorando um processo que havia encontrado anos antes enquanto procurava fontes para outra pesquisa, mas deixado de lado, esperando outro momento mais propício. 


\section{Escritas do Tempo}

Tratava-se de um caso emblemático, que a habilidade do autor fez tornar-se único por sua análise inovadora. Um moleiro que vivia na aldeia de Montereale, na região do Friuli do século XVI, perseguido pela Inquisição pontifícia por suas ideias heréticas e uma visão de mundo totalmente avessa ao que pregava a Igreja. Domenico Scandella, conhecido como Menocchio, o tal moleiro retratado na obra, gostava de falar (causa de sua delícia e desventura...), e o seu julgamento foi oportunidade para expor a uma audiência maior do que a do vilarejo em que vivia sua cosmogonia, como um enorme queijo cheio de vermes. Apesar de alfabetizado e leitor de alguns livros, poderia ser visto, indica Ginzburg, como uma espécie de porta-voz de uma cultura que era, na essência, tradicional, oral e popular. Era, enfim, fruto de seu tempo, como diz o autor em seu prefácio à edição italiana:

Dois grandes eventos históricos tornaram possível um caso com o de Menocchio: a invenção da imprensa e o advento da Reforma. A imprensa lhe permitiu confrontar os livros com a tradição oral em que havia crescido e lhe forneceu as palavras para organizar o amontoado de ideias e fantasias que nele conviviam. A Reforma lhe deu audácia para comunicar o que pensava ao padre do vilarejo, conterrâneos, inquisidores - mesmo não tendo conseguido dizer tudo diante do papa, dos cardeais e dos príncipes, como queria (GINZBURG, 1996, p. 33).

Nas palavras de Vainfas (2002, p. 82), a situação limite de Menocchio, "na fronteira entre a cultura letrada das elites e a experiência de uma cultura popular transmitida oralmente, eis o que, por meio da saga deste moleiro italiano, Ginzburg apresenta para o leitor especializado e interessado" - mas não só - "no conceito de circularidade cultural que o personagem encarna”.

O impacto da obra foi imediato: muito bem recebida na Itália, rapidamente traduzida e publicada em outros países (teve, pelo menos, publicação em 18 idiomas), abraçada como uma espécie de manifesto da "história vista de baixo", da antropologia histórica, e virou marco da chamada Micro-História. Alcançou limites para além das fronteiras acadêmicas, entre leitores não especializados - a ponto de ser vendido nas máquinas automáticas do metrô de Paris -, interessados no enredo apresentado em leitura agradável e sem rigorismos acadêmicos usuais - embora de profundidade histórica e metodológica indiscutível. O Queijo e os vermes tornou-se contribuição inestimável para a historiografia sobre a Inquisição e as religiosidades, sendo referência para o que vem depois, seja apoiando ou criticando suas ideias. Passados mais de quarenta anos de seu lançamento, continua a influenciar historiadores de renome, que encontraram na 


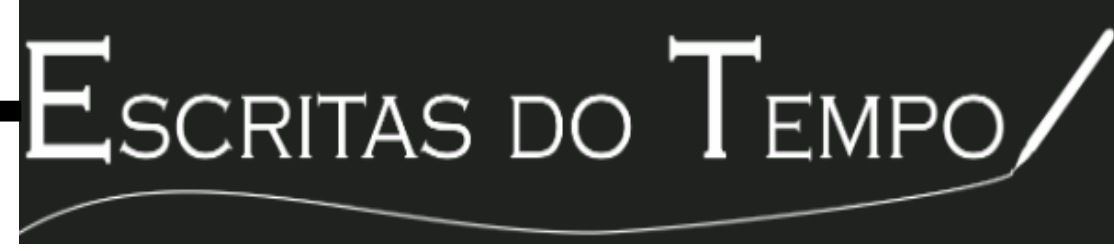

estruturação da obra inspiração para estudos renovadores sobre a Modernidade. Um deles, mais recentemente, foi Stuart Schwartz, que inicia o seu brilhante Cada um na sua Lei declarando a inspiração do Menocchio de Ginzburg para a concepção de seu livro:

Este livro foi concebido na cama. Lembro-me de rir alto, numa noite de inverno em Minneapolis, ao ler O Queijo e os vermes, de Carlo Ginzburg, imaginando como fora tolerante e moderno o moleiro e livre-pensador friulano Menocchio quando disse a seus inquisidores, em 1584, que ninguém sabia realmente qual era a melhor religião; e que embora, claro, fosse católico, se tivesse nascido entre os turcos teria vivido na religião deles achando que era a melhor. A salvação era possível em qualquer religião, dizia ele, porque Deus ama a todos nós. E pensei: que curioso, que sensato, que singular! Ainda dando risada, apaguei a luz. A vida continuou; a passagem foi esquecida. Dez anos depois, trabalhando nos arquivos da Inquisição espanhola sobre as ideias de sexualidade na Espanha e em suas colônias, comecei a encontrar casos de pessoas com atitudes perante as outras religiões muito parecidas com as de Menocchio. Na maioria era gente simples, mas alguns clérigos e leigos instruídos também expressavam ideias de tolerância e relativismo religioso, muitas vezes resumidas numa mesma frase: cada uno se puede salvar em su ley [cada um pode se salvar em sua lei]. Como era possível esse tipo de relativismo ou tolerância no início da Idade Moderna em Portugal e na Espanha, os exemplos clássicos da ortodoxia imposta pela Reforma católica? Quem eram essas pessoas e de onde haviam tirado tal ideia? Aquilo desafiava todas as minhas suposições sobre o passado de Portugal, da Espanha e de suas respectivas colônias na América Latina, e senti minha curiosidade espicaçada. Assim nasceu este livro (SCHWARTZ, 2009, p. 15-16).

Também, pudera! O livro colocava holofotes em questões que se tornariam, doravante, cada vez mais frequentes em trabalhos da historiografia: as análises microanalíticas, os códigos sociais e comportamentais, a circularidade cultural, o método indiciário. De acordo com Roger Chartier,

Como nos mostra Carlo Ginzburg, quando os documentos autorizam, é inteiramente permitido explorar, como se por uma lente de aumento, a maneira como um homem do povo pode pensar e usar os elementos intelectuais esparsos da cultura literária que o alcançam por meio de seus livros e da leitura que ele faz deles. Aqui, Bakhtin é posto de ponta cabeça, uma vez que um sistema de representações é construído a partir dos fragmentos emprestados da cultura acadêmica e livresca, aos quais outros significados são atribuídos, pois no fundamento do sistema há uma outra cultura: "por trás dos livros que Menocchio ruminava, identificamos um código de leitura e, por trás dele, um estrato sólido de cultura oral" (CHARTIER, 1982, p. 35-36).

No Brasil, O queijo e os vermes inaugurou a publicação de livros do autor, em 1987, pela Companhia das Letras, ainda hoje, editora responsável pelo lançamento da maior parte de suas obras. Foi publicado antes de Andarilhos do bem, lançado no ano 


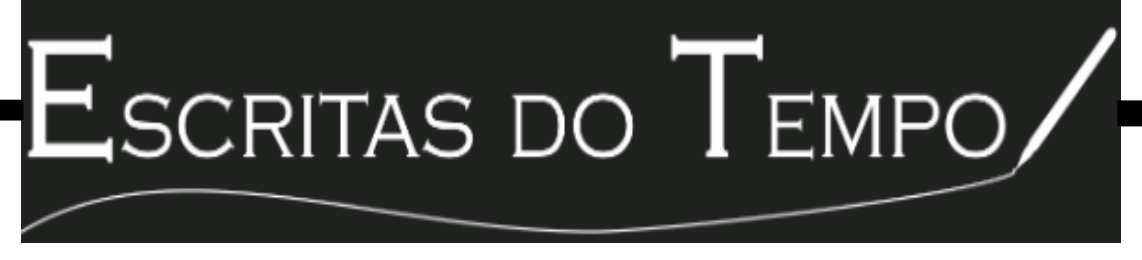

seguinte aqui no país, mas escrito e lançado antes na Itália. Contou, além dos prefácios às edições inglesa e italiana, com um posfácio de Renato Janine Ribeiro, Ministro da Educação durante o governo Dilma Rousseff. Antes mesmo de sua publicação, porém, já circulava na Academia em edições estrangeiras, utilizado como bibliografia de disciplinas de graduação e pós-graduação, assim como referência de dissertações e teses defendidas nos anos 1980. Aparece, assim, como bibliografia citada em duas das obras inauguradoras dos estudos de história cultural no Brasil e que serviram de referência para os historiadores a partir de então.

Em O Diabo e a Terra de Santa Cruz, obra incontornável aos que estudam as religiões e as religiosidades, cuja primeira edição é de 1986, logo, antes da publicação do livro de Ginzburg no Brasil, aparece citado por Laura de Mello e Souza em sua versão francesa, Le fromage et les vers, assinada em Paris pela Gallimard (s/d). Tece, então, paralelismos entre os personagens da luso-América que retrata com o Menocchio de Ginzburg, comparando como indivíduos em espaços e tempos tão distintos pregavam ideias parecidas, como a simplificação da religião, o abandono dos sacramentos e a crença somente em Deus, sem a intervenção dos representantes da Igreja (SOUZA, 1993, p. 103). Foi o livro de Laura pioneiro no modo de retratar, de acordo com Vainfas,

as crenças populares no Novo Mundo nos termos em que Carlo Ginzburg concebeu o conflito entre Menocchio e a Inquisição italiana no século XVI. Um conflito entre a visão de mundo camponesa, tradicional, transmitida oralmente, e a visão de mundo letrada, austera, dogmática. Conflito de classes e conflito de culturas, a um só tempo, no qual Menocchio ficaria no meio, como intermediário cultural ou protagonista de circularidades (VAINFAS, 2009, p. 231).

Também em Trópico dos Pecados, livro igualmente importante para os estudos sobre religião e religiosidades na América portuguesa, publicado prima volta em 1989, Ronaldo Vainfas da mesma forma cita $O$ queijo e os vermes em seu compêndio bibliográfico. Estas duas obras e, principalmente, seus dois autores, das grandes referências sobre a historiografia de cunho cultural produzida em dois dos principais programas de pós-graduação do país, formaram novas gerações de pesquisadores com suas leituras e produções influenciadas pelo livro (assim como pela obra como um todo) de Ginzburg. Embora as questões sobre história cultural marcassem trabalhos de gerações anteriores, tanto Laura de Mello e Souza quanto Ronaldo Vainfas usam e abusam, no melhor sentido, da noção de cultura como "jaula flexível e invisível dentro da qual se 


\section{Escritas do Tempo/}

Inquisição. Embora a historiografia contemporânea sobre o tema tenha completado cinquenta anos, com os estudos clássicos de autores como Sonia Siqueira e Eduardo d'Oliveira França, José Gonçalves do Salvador, Elias Lipiner e Anita Novinsky, é a partir da geração formada nos programas de pós-graduação dos anos 1980, principalmente na USP (além de Vainfas e Laura, Mary del Priore, Lana Lage, Luiz Mott, Leila Algranti e tantos outros...) utilizaram fontes inquisitoriais para estudar não apenas a ação do Santo Ofício, mas um infinito (no melhor sentido) saco sem fundo de assuntos presentes nesta documentação.

Mas, sem dúvida, os estudos inquisitoriais ganharam força, influenciados por estas obras que, por sua vez, beberam na fonte ginzburguiana, e atualmente, fosse possível fazer referência, pelo menos, a uma terceira ou quarta gerações de autores e obras no Brasil embasados pela leitura de $O$ Queijo e os Vermes. A forma como o autor trabalha as fontes inquisitoriais é inspiração para todos que estudam o assunto. Ainda hoje não são poucos os trabalhos defendidos ou em andamento em programas de pós-graduação espalhados por todo o país influenciados pelo estudo de Ginzburg sobre Domenico Scandella, o Menocchio. Destacam-se as já clássicas abordagens de Luiz Mott - Mott, cabe lembrar, fez parte do grupo que desenvolvia seu doutoramento junto com Laura, Ronaldo, Lana Lage, Mary del Priore na USP dos 80 -, com a Rosa Egipcíaca, e de Plinio Freire Gomes sobre Pedro de Rates Henequim em seu Um herege vai ao paraíso, pesquisa orientada por Laura de Mello e Souza, ou ainda, o estudo da Santidade de Jaguaripe feita por Vainfas em A Heresia dos Índios e que, cada uma ao seu modo, apresentam elementos próximos à análise proposta pelo historiador italiano, como o estudo de microanálise, das mediações e substratos culturais e da flexibilização da ideia de cultura, dos filtros de leitura e interpretação (ideia que tão bem explora no famoso artigo $O$ inquisidor como antropólogo), do método indiciário... Não há hoje, enfim, trabalho sério que estude Inquisição, cultura popular ou religiosidades que não tenha Ginzburg entre suas referências biliográficas obrigatórias.

Atualmente, os antigos orientandos de Ronaldo, Laura, Mott, Lana e demais pesquisadores que primeiro devoraram $O$ Queijo e os Vermes têm e formam novas gerações de orientandos e pesquisadores, que ocupam espaço em universidades de Norte a Sul do país, e que indicam este livro como uma das primeiras leituras aos interessados no tema. Assim, a obra de Ginzburg se renova, relida a cada nova pesquisa, ganhando 
coletivo, ou simples demais, como o acaso. Decerto, Menocchio falava de um queijo bem real, nada mítico, o queijo que vira ser feito (ou que talvez ele próprio tivesse feito) inúmeras vezes. [...] Não se pode excluir o fato de que ela constitua uma das provas, fragmentária e em parte extinta, da existência de uma tradição cosmológica [milenária] que, ultrapassando as diferenças de linguagem, combina mito e ciência. No caso de Menocchio é impossível pensar em transmissão direta - transmissão oral, de geração para geração. Essa hipótese parece menos improvável se pensarmos na difusão - durante os mesmos anos e justamente no Friuli - de um culto de base xamanista como o dos benandanti. A cosmogonia de Menocchio se localiza nesse terreno, ainda quase inexplorado, de relações e migrações culturais (GINZBURG, 1987, p. 110-112).

Vale ressaltar que a tradução brasileira de Maria Betânia Amoroso com revisão técnica de Hilário Franco Jr. suprimiu a palavra “milenária”, o que não ocorre nas edições italianas $(1976,1999,2009)$. Quem o fez, em verdade, retirou um dos "calcanhares de Aquiles" do conceito de cultura popular de Ginzburg, afinal essa concepção "milenar" identifica a cultura popular como "um resto primitivo". Se, por um lado, a religião popular é perigosamente percebida como algo puro e exótico que permaneceu inalterado no tempo (tal como se estivesse desde sempre coberta e precisasse apenas ser desvelada), por outro, promove uma perfeita compreensão de que o processo de "disciplinamento social" não foi capaz de apagar uma cultura própria dos populares.

Para alguns críticos, entretanto, Menocchio não teria qualquer relação com a cultura popular. Ainda em 1976, Giorgio Spini publicou uma resenha na Rivista storica italiana discordando de Ginzburg ao apontar que Menocchio não pertenceria à cultura campesina (como, aliás, afirma Renato Janine Ribeiro no posfácio de $O$ Queijo e os Vermes ${ }^{9}$ ), mas que manifestaria a penetração de uma cultura erudita anticristã e antirreligiosa dos libertinos e de naturalistas, de Pádua a Giordano Bruno (SPINI, 1976, p. 792-802) - este último, vale ressaltar, queimado no mesmo momento que Menocchio. Paola Zambelli, por sua vez, procurou vincular a "fermentação cosmológica" do queijo de Menocchio com o platonismo de Marsílio Ficino e o aristotelismo de Avicena e Averroes renascidos no século XV e XVI em Pádua e Veneza (ZAMBELLI, 1979, p. 5190).

As interpretações de Spini ou Zambelli inverteram a lógica popular de Ginzburg, associando o moleiro com movimentos eruditos da Europa do século XVI. Luca Addante descartou completamente essa vinculação, preferindo uma associação mais palpável de

\footnotetext{
${ }^{9}$ Renato Janine teria caracterizado Menocchio como alguém de "classe média", devido a sua profissão de moleiro. Difícil, porém, seria conceber o que seria uma classe média no século XVI.
} 
Menocchio com as ideias anabatistas de Giulio Basalù, sobretudo no que concerne à visão radical antitrinitária e uma perspectiva materialista da vida (ADDANTE, 2009 e 2010).

A publicação dos dois processos contra Domenico Scandella por Andrea Del Col permitiu aos leitores o acesso às fontes - ponto-chave da crítica a Ginzburg, que não teria permitido o acesso ao texto por seus leitores. A publicação multiplicou as interpretações e o próprio Del Col consagrou a ligação de Scandella com os Cátaros no norte da Itália (DEL COL, 1990), ao que foi seguido por Sergio Bertelli (1984). Mais recentemente, David Levine e Zubedeh Vahed (2001, p. 437-464) apontaram a influência inequívoca do Alcorão na visão de mundo de Menocchio.

É preciso perceber que o que está em jogo nessas interpretações historiográficas são as origens das ideias heterodoxas de Menocchio. Nesse sentido, Del Col e os demais historiadores estão menos interessados nas leituras de Scandella centrando força na decomposição das ideias do moleiro em relação às ideias e movimentos existentes no norte da Itália no início do século XVI. Enquanto Ginzburg procura compreender Menocchio pela relação da cultura popular com as leituras que fez, criando algo expressamente novo, Del Col procura situá-lo em uma corrente existente. Se para Donald Weinstein (1994, p. 179) a principal vantagem da hipótese de Del Col sobre a de Ginzburg foi a de que ao menos os Cátaros haviam existido, é certo que ambos, entretanto, não conseguiram demonstrar como operou a transmissão dos saberes que constituíram a cosmogonia de Scandella. A tradição milenar da cultura popular oral somente é referenciada por Carlo Ginzburg de maneira genérica, assim como a associação entre o catarismo, os valdenses, os libertinos, etc., permanece sem ser comprovada.

Interessante perceber que este é um ponto de autocrítica que Ginzburg faz ao seu próprio trabalho. Em I benandanti (Os andarilhos do bem), estudo sobre as atitudes religiosas e a mentalidade de uma sociedade camponesa no Friuli, entre os séculos XVI e XVII, o núcleo de crenças populares - assimiladas à feitiçaria pelos inquisidores - foi interpretado por Ginzburg à luz da "história das mentalidades". Contudo, na segunda edição - pós-escrito de 1972 - o autor, num esforço de autocrítica, lançou seu descontentamento ante às mentalidades e à "ingênua contraposição entre 'mentalidade coletiva' e 'atitudes individuais"” (GINZBURG, 1998, p. 15-16). Mas foi no prefácio de $O$ queijo e os vermes que tratou melhor suas discordâncias com a "história das mentalidades". Diz ele: 
o que tem caracterizado os estudos de história das mentalidades é a insistência nos elementos inertes, obscuros, inconscientes de uma determinada visão de mundo. As sobrevivências, os arcaísmos, a afetividade, a irracionalidade delimitam o campo específico da história das mentalidades, distinguindo-a com muita clareza de disciplinas paralelas e hoje consolidadas, como história das ideias ou a história das culturas (GINZBURG, 1987, p. 28).

Assim, contra a "conotação interclassista" das mentalidades sugere que "uma análise de classes é sempre melhor que uma interclassista" (GINZBURG, 1987, p. 29), propondo a substituição conceitual e teórica de "mentalidade coletiva" por "cultura popular".

Seu conceito de "cultura popular", apoiado na antropologia, define-se como um "conjunto de atitudes, crenças, códigos de comportamento próprios das classes subalternas num certo período histórico" (GINZBURG, 1987, p. 16), pois "a cultura oferece ao indivíduo um horizonte de possibilidades latentes - uma jaula flexível e invisível dentro do qual se exercita a liberdade condicionada de cada um" (GINZBURG, 1987, p. 25). Nesse sentido, tece suas críticas tanto a Magistrados e feiticeiros, de Robert Mandrou, como a Littérature populaire et littérature de colportage au XVIII e siècle, de Geneviève Bollème.

Enquanto para o primeiro, Ginzburg aponta a diferença entre "cultura popular" e "cultura imposta às classes populares", que se traduziria em passividade das classes subalternas (GINZBURG, 1987, p. 18), para a segunda, afere que de forma alguma a "literatura de cordel” é expressão espontânea, original e autônoma das classes populares (GINZBURG, 1987, p. 19). Questiona: “Até que ponto a primeira [cultura das classes subalternas] está subordinada à segunda [cultura das classes dominantes]? Em que medida, ao contrário, exprime conteúdos ao menos em parte alternativos? É possível falar em circularidade entre os dois níveis de cultura?” (GINZBURG, 1987, p. 17)

Para responder a estas questões, todavia, Ginzburg (1987, p. 64) segue uma pista deixada por Menocchio: "Senhor [respondendo aos juízes], nunca encontrei alguém que tivesse essas opiniões. As minhas opiniões saíram da minha própria cabeça”; estas “opiniões saíram de sua própria cabeça” (GINZBURG, 1987, p. 80). Ou quando fala sobre a leitura: “(...) sobre isso eu li no Fioretto della Bibbia, mas as outras coisas que eu disse sobre o caos eu tirei da minha própria cabeça" (GINZBURG, 1987, p. 97). Por isso, talvez não seja tão correto afirmar que Ginzburg tenha pretendido, com O queijo e os vermes, desvendar a cultura popular através "de um único exemplo, de um único processo 


\section{Escritas do T EMPo/}

inquisitorial", como disseram seus críticos (VAINFAS, 1997, p. 152). Menocchio, protagonista do livro, não personifica a cultura popular em si, mas a dinâmica relação entre os diferentes níveis culturais, processo chamado de circularidade cultural. Assim, é necessário entender o que Ginzburg chama de "circularidade cultural”? Inspirado em Mikhail Bakhtin (A cultura popular na Idade Média e no Renascimento), Ginzburg lança mão do conceito de Circularidade cultural. Se, por um lado, "cultura popular" define-se em oposição à "cultura letrada" ou das "classes dominantes", por outro, é na relação que mantém com a cultura dominante, filtrada pelos seus valores e experiências de vida, que acura o conceito. A relação entre estes níveis culturais, popular e erudito, é dinâmica, relacional, e nunca podem ser vistas como isoladas.

Ginzburg procura construir as modalidades de leitura de Domenico Scandella e, para isso, coloca lado a lado as falas e os textos que confessa ter lido, como: As viagens de Mandeville; Il fioretto della Bibbia; Bíblia em língua vulgar; Alcorão; duas novelas do Decamerão; etc. Assim, Ginzburg faz uma genealogia das crenças e das representações de Menocchio colocadas sob um exegético de incrível erudição. Ou seja, o historiador italiano promove uma cartografia das leituras de Domenico Scandella, realiza uma exegese (ou hermenêutica) desses textos a partir das próprias respostas dadas aos inquisidores e procura perceber as originalidades de leituras conferidas a partir da cultura popular. O problema é que muitas das hipóteses e interpretações de Ginzburg (1987, p. 200) são, como ele mesmo afirma, “em parte, impossível de demonstrar”, afinal o estudo da cultura popular (ou subalterna) impõe "critérios de verificação distintos que os habituais" - e "novas exigências de pesquisa criam novas lacunas" (GINZBURG, 2007, p. 421).

Tais posições expõem certa fragilidade à interpretação de Ginzburg sobre Menocchio. Ronaldo Vainfas (2002, p. 98-103) afirma que são parte constitutiva do fazer histórico da micro-história e Ginzburg lembra que "os obstáculos postos à pesquisa eram elementos constitutivos da documentação, logo deviam tornar-se parte do relato". Os "talvez" e "pode ser" que compõem a pesquisa fazem da História um horizonte de possibilidades controladas que, diferente do juiz, onde a incerteza tem significado negativo, para o historiador ela é lide de todo o dia. É assim que o fabuloso ensaio "Sinais: raízes de um paradigma indiciário" aparece para o historiador italiano com a ambição de construir um novo paradigma: o indício é transformado em prova, e a dúvida, a "realidade opaca", em narrativa. Aponta Ginzburg: 
Nesse ponto, abriam-se duas vias: ou sacrificar o conhecimento do elemento individual à generalização (mais ou menos rigorosa, mais ou menos formulável em linguagem matemática), ou procurar elaborar, talvez às apalpadelas, um paradigma diferente, fundado no conhecimento científico (mas de toda uma cientificidade por definir) do individual (GINZBURG, 1990, p. 163).

Dessa forma, cria uma metáfora em que o historiador assemelha-se com um detetive, médico ou caçador primitivo: a) o médico, apenas observando atentamente e registrando com extrema minúcia todos os sintomas do paciente, elabora histórias precisas de cada doença: “a doença é, em si, inatingível” (GINZBURG, 1990, p. 155); b) o detetive (Sherlock Holmes, de Conan Doyle) investiga e desvenda os crimes através de indícios imperceptíveis à maioria (GINZBURG, 1990, p. 145); c) o caçador primitivo aprendeu a farejar, registrar, interpretar e classificar pistas infinitesimais para a construção de um saber venatório que remonta a uma realidade complexa e não experimentável diretamente: “'decifrar' ou 'ler' as pistas dos animais são metáforas” (GINZBURG, 1990, p. 151-153).

Ginzburg procura mostrar com essas alegorias que a História é uma ciência do particular, que tem um saber indiciário e produz o conhecimento lendo e interpretando os sinais, as pistas e os indícios do mundo. Sublinha:

Se as pretensões de conhecimento sistemático mostram-se cada vez mais como veleidades, nem por isso a ideia de totalidade deve ser abandonada. Pelo contrário: a existência de uma profunda conexão que explica os fenômenos superficiais é reforçada no próprio momento em que se afirma que um conhecimento direto de tal conexão não é possível. Se a realidade é opaca, existem zonas privilegiadas - sinais, indícios - que permitem decifrá-la (GINZBURG, 1990, p. 151-177).

Esse é o ponto chave de seu paradigma. Particularidades diminutas foram empregadas como pistas das mais diversas que permitiam reconstruir trocas e transformações culturais, antes opacas e obscuras da realidade histórica. No particular, na Microanálise, na redução da escala de pesquisa o historiador pode compreender melhor a totalidade, pois a soma das partes sempre é maior que o todo ${ }^{10}$. Dessa forma, a História é a ciência do particular, do caso irrepetível e único e não ciência universalista de tipo

\footnotetext{
${ }^{10}$ Porém, o outro lado da relação dialética entre as partes e o todo é que sem o conhecimento ou a referência ao todo, as partes são ininteligíveis. As partes tornam-se obscuras sem a totalidade, ou mesmo o contexto, assim como, com o todo descolado das partes, fazem-se apenas generalizações.
} 


\section{Escritas do T EMPo/}

"galileano", pois no que diz respeito ao paradigma indiciário "trata-se de formas de saber tendencialmente mudas - no sentido de que (...) suas regras não se prestam a ser formalizadas nem ditas" (GINZBURG, 1990, p. 179).

Como era de se esperar, tais formulações promoveram uma enxurrada de críticas e dúvidas quanto à construção histórica que Ginzburg fez da cultura popular de Menocchio. Alguns historiadores indagaram como seria possível compreender toda uma cultura popular através das leituras de Scandella. Assim, a questão, nesse ponto das críticas, era não mais a origem das ideias do moleiro, mas como ele lia o mundo. Para alguns historiadores, como Jean Boutier e Philippe Boutry (2013), os conceitos de "apropriação" e "representação" teriam melhor utilidade para o estudo deste caso. Danilo Zardin (2001, p. 57) também insistiria nesse ponto, descartando completamente a ideia de "religião popular" em favor da "pluralidade de formas concomitantes de ‘apropriação"”. Nesse aspecto, vale citar a própria crítica traçada por Roger Chartier:

Atribuir a categoria de "popular" a modos de ler, e não a classes de textos, é, ao mesmo tempo, essencial e arriscado. Após o estudo exemplar de Carlo Ginzburg, tem sido muito grande a tentação de caracterizar a leitura popular a partir da de Menocchio - ou seja, como uma leitura descontínua que desmembra os textos, descontextualiza as palavras e as frases, limita-se à literalidade do sentido. Este tipo de diagnóstico encontrou confirmação na análise das estruturas - ao mesmo tempo textuais e materiais - dos impressos destinados ao grande público, cuja organização em sequências breves e desconjuntadas, encerradas em si mesmas, repetitivas, parece adequar-se a uma leitura picotada, sem memória, sustentada por fragmentos do texto (CHARTIER; 1985, p. 188).

Segue o historiador francês encaminhando para uma questão: "Será que as práticas de leitura que se considera como especificamente populares, enraizadas numa antiga cultura oral e camponesa, são (elas e outras modalidades) diferentes das que, na mesma época, caracterizam a leitura dos letrados? (CHARTIER; 1985, p. 188). Chartier entende que a "cultura popular" é compreendida frequentemente como (1) “um sistema simbólico coerente e autônomo, que funciona segundo uma lógica absolutamente alheia e irredutível à da cultura letrada"; ou também pode ser (2) concebida "em suas dependências e carências em relação à cultura dos dominantes" (CHARTIER; 1985, p. 179). Em termos parecidos, Jacques Revel aponta que:

esse [Menocchio] semiletrado, autodidata, montou uma biblioteca (...) aproveitando as oportunidades e, em todo caso, no exterior de toda a disciplina cultura. Seu emprego do livro é selvagem: ele consiste em fazer uma leitura 
descontextualizada, que tira proveito onde decide encontrá-lo. Menocchio desvia os conteúdos de sentido para reorganizá-los segundo as lógicas e as exigências de outra cultura na qual Ginzburg estima, com ou sem razão, que ela manifeste a persistência de uma base pré-cristã muito antiga. O que, no entanto, parece-me distintivo nas práticas de leitura do moleiro friulano, não é fundamentalmente o ressurgimento de um estrato cultural mais antigo e mais profundo, mas, antes de tudo, o fato deles obedecerem a normas que revogam aquelas que a cultura legítima institui. O popular constrói-se assim em um desvio (que pode ser imposto, reivindicado ou simplesmente constatado) das regras do jogo (REVEL, 2009, 180).

Ambos os autores partem da premissa de que o termo popular foi definido pelo erudito tout court. Por isso, assume a imagem de uma "origem perdida: a ficção de uma realidade a encontrar mantém a marca da ação política que a organizou" (REVEL \& CERTEAU, 1989, p. 63). A cultura popular é como a "beleza de um morto": belo, inofensivo e eficaz. É claro que a referência se faz com a littérature de colportage, mas também à cultura popular milenária de Ginzburg. Porém, vale ressaltar, Ginzburg não toma a cultura de Menocchio como coerente e autônoma, mas como supreendentemente construída na relação entre o popular (sua expressão social) e erudita (através da leitura de livros). O historiador italiano não opõe de forma maniqueísta e mecânica as expressões "popular" e "erudito", mas interpreta e narra a cultura de Menocchio nos interstícios destas duas categorias. É através de Domenico Scandella que Ginzburg chega à “circularidade cultural”, seu objetivo; mas também “O queijo e os vermes não se limita a reconstruir uma história individual: conta-a" (GINZBURG, 2007, p. 264).

A reconstrução do mundo intelectual, moral e fantasioso do moleiro do Friuli experimentou, como poucos objetos de pesquisa, certa inflação interpretativa limitada pela escassez de fontes circunstanciada por dois pequenos processos inquisitoriais e, quando muito (excetuando Carlo Ginzburg), os livros que Menocchio afirmou ter lido. Envoltos de uma verdadeira e constante batalha interpretativa que ultrapassa 40 anos, $O$ queijo e os vermes e a vida de Menocchio ainda tem muito a ensinar aos historiadores experientes e vindouros. Ginzburg teve o mérito de trazer ao público a possibilidade de conhecer a vida de pessoas comuns, estendendo o conceito de indivíduo às classes populares, como ele mesmo afirma no prefácio. Que mais Menocchios sejam descobertos e façam a História de carne, osso e muito, mas muita interpretação e debate. Afinal, como no conto de Gabriel Garcia Marques, O afogado mais bonito do mundo, apenas um "morto" pode dar vida a uma ilha tão pobre de si. 


\section{Escritas do Tempo/}

$* * *$

Em sua versão original, este texto foi gestado e apresentado no âmbito do Seminário $O$ Queijo e os Vermes 40 anos depois, realizado pelo Núcleo de Estudos Coloniais - MANTO, e que foi parte da VI Semana de História da UNIRIO, tendo ocorrido no dia 07 de novembro de 2016. O seminário foi organizado pelo Professor Paulo Cavalcante, que faleceu poucos meses depois do evento. Retornar a este texto e permitir, pela publicação o seu acesso a um grupo maior de pessoas, multiplicando vozes, é uma das formas de homenagearmos ao querido amigo Paulo, defensor de uma História combativa e democrática. Assim como Ginzburg, Paulo sempre acreditou e defendeu que o conhecimento histórico deveria alcançar um público mais amplo. Onde estiver, continua conosco, tal qual nos ensinou Penélope, no firme e necessário propósito de retecer o passado.

\section{Referências}

ADDANTE, Luca. 'Hérésie radicale et libertinage. Le valdésien Giulio Basalù et Domenico Scandella dit Menocchio'. In: J.-CAVAILlÉ, P., MOLHO, A. (Orgs.). Dissidence et dissimulation, «Les dossiers du GRIHL», 2009.

ADDANTE, Luca. Eretici e libertini nel Cinquecento italiano. Bari: Laterza, 2010.

ANGELI, Pietro. Gramsci, De Martino e la crise della scienza del folclore. In: BARATTA, G.; CATONE, A. (Orgs.). Antonio Gramsci e il "progresso intellettuale di massa”. Milano: Unicopli, 1995.

BAKHTIN, Mikhail. A cultura popular na Idade Média e no Renascimento: o contexto de François Rabelais. 3ª ed. São Paulo: Hucitec; Brasília: EdUnb, 1996.

BERTELLI, Sergio. Rebeldes, libertinos y ortodoxos en el Barroco. Barcelona: Península, 1984 (1973).

BOUTIER, Jean \& BOUTRY, Philippe. 'L'invention historiographique'. Enquête [En ligne], 3, 1996, mis en ligne le 11 juillet 2013.

CHARTIER, Roger. Intellectual History or Sociocultural History? The French Trajectories. In: LACAPRA, Dominick; KAPLAN, Steven L. (Orgs.). Modern European Intellectual History: Reappraisals and New Perspectives. Ithaca: Cornell University Press, 1982. 


\section{Escritas do Tempo/}

CHATIER, Roger. Cultura popular: revisitando um conceito historiográfico. Estudos Históricos, Rio de Janeiro, v. 8, n. 16, 1985.

DEL COL, Andrea (Ed.). Domenico Scandella detto Menocchio: i processi dell'Inquisizione (1583-1599). Pordenone: Edizioni Biblioteca dell'Immagine, 1990.

DE MARTINO, Ernesto. Il mondo magico: prolegomeni a una storia del magismo. Torino: Einaudi, 1949.

DE MARTINO, Ernesto. Magia e civiltà. Milano: Garzanti, 1962.

GINZBURG, Carlo. Indagações sobre Piero: o Batismo, o Ciclo de Arezzo, a Flagelação. Rio de Janeiro: Paz e Terra, 1989.

GINZBURG, Carlo. Os andarilhos do bem: feitiçarias e cultos agrários nos séculos XVI e XVII. $1^{a}$ reimp. São Paulo: Companhia das Letras, 1990.

GINZBURG, Carlo. Mitos, emblemas, sinais: morfologia e história. $1^{\text {a }}$ reimp. São Paulo: Companhia das Letras, 1990.

GINZBURG, Carlo. História noturna: decifrando o sabá. São Paulo: Companhia das Letras, 1991.

GINZBURG, Carlo. El juez y el historiador. Acotaciones al margen del caso Sofri. Madrid: Anaya \& Mario Muchnik, 1993.

GINZBURG, Carlo. O queijo e os vermes: o cotidiano e as idéias de um moleiro perseguido pela Inquisição. $8^{\text {a }}$ reimp. São Paulo: Companhia das Letras, 1996.

GINZBURG, Carlo. A Micro-História e outros ensaios. Rio de Janeiro: Bertrand, 1989.

GINZBURG, Carlo. Olhos de madeira: nove reflexões sobre a distância. São Paulo: Companhia das Letras, 2001.

GINZBURG, Carlo. Relações de força: história, retórica, prova (2000). São Paulo: Companhia das Letras, 2002.

GINZBURG, Carlo. Nenhuma ilha é uma ilha: quatro visões da literatura inglesa. São Paulo: Companhia das Letras, 2004.

GINZBURG, Carlo. Tentativas. Rosario: Prohistoria ediciones, 2004.

GINZBURG, Carlo. O fio e os rastros: verdadeiro, falso, fictício. São Paulo: Companhia das Letras, 2007.

GINZBURG, Carlo. Medo, reverência, terror: quatro ensaios de iconografia política. São Paulo: Companhia das Letras, 2014. 


\section{Escritas do Tempo/}

GRAMSCI, Antonio. Caderno dos cárceres. Tradução de Carlos Nelson Coutinho. Rio de Janeiro: Civilização Brasileira, 2002.

LE GOFF, Jacques; NORA, Pierre. História: novos objetos. Rio de Janeiro: Francisco Alves, 1976.

LE GOFF, Jacques; NORA, Pierre. História: novos problemas. Rio de Janeiro: Francisco Alves, $2^{\mathrm{a}}$ edição, 1979.

LE GOFF, Jacques; NORA, Pierre. História: novas abordagens. Rio de Janeiro: Francisco Alves, 1988.

LEVI, Giovanni. A herança imaterial: trajetória de um exorcista no Piemonte do século XVII. Rio de Janeiro: Civilização Brasileira, 2000.

LEVINE, David; VAHED, Zubedeh. 'Ginzburg's Menocchio: Refutations and Conjectures'. Histoire Sociale/Social History: vol. 34, n. 68 (2001).

LIMA; Henrique Espada. A micro-história italiana: escalas, indícios e singularidades. Rio de Janeiro: Civilização Brasileira, 2006.

REVEL, Jacques; CERTEAU, Michel de; JULIA, Dominique. A beleza do morto: o conceito de cultura popular. In: REVEL, Jacques. A invenção da sociedade. Lisboa: Difel, 1989.

REVEL, Jacques. Proposições: ensaios de História e historiografia. Rio de Janeiro: Ed. UERJ, 2009.

SCHWARTZ, Stuart. Cada um na sua lei: tolerância religiosa e salvação no mundo atlântico ibérico. São Paulo: Companhia das Letras; Bauru: EDUSC, 2009.

SOUZA, Laura de Mello e. O diabo e a Terra de Santa Cruz: feitiçaria e religiosidade popular no Brasil colonial. $3^{\text {a }}$ reimp. São Paulo: Companhia das Letras, 1993.

SPINI, G. Noterelle libertino. Rivista storica italiana, LVIII, 1976.

VAINFAS, Ronaldo. História das mentalidades e história cultural. In: CARDOSO, Ciro Flamarion e VAINFAS, Ronaldo. Domínios da história. Rio de Janeiro: Campus, 1997.

VAINFAS, Ronaldo. Micro-história: os protagonistas anônimos da História. Rio de Janeiro: Campus, 2002.

VAINFAS, Ronaldo. História cultural e historiografia brasileira. História: Questões \& Debates, Curitiba, n. 50, p. 217-235, jan./jun. 2009. Editora UFPR.

ZAMBELLI, Paola. Uno, due, mille Menocchio?. Archivio storico italiano, CXXXVI, 1979. 
ZARDIN, Danilo. 'La "religione popolare": interpretazioni storiografiche e ipotesi di ricerca'. In: Memorandum, 1, 2001.

WEINSTEIN, Donald. Journal of Modern History, LXVI, 1994, p. 179.

Artigo recebido em 29 de março de 2019 e aprovado em 10 de junho de 2019. 